\title{
Registros contables en los Comités de Agua Potable y Saneamiento (CAPS) en Nueva Guinea, 2014
}

\author{
Julia Yunieth Aguilar Brenes ${ }^{1}$ \\ Marlen Jarelys Jarquin Villachica ${ }^{2}$ \\ Mibsam Aragón Gutiérrez ${ }^{3}$
}

\section{Resumen}

I os registros contables realizados en su práctica organizativa los CAPS en 5 comunidades de Nueva LGuinea en el período 2014, se corresponden en su mayoría con la normativa que les rige ley 722 Ley Especial de Comités de Agua Potable y Saneamiento; asimismo, no existe seguimiento y acompañamiento de parte de las diferentes entidades que tienen competencia en este tema, y la población participa de forma limitada en las distintas actividades convocadas por la junta directiva de los Comité de Agua Potable y Saneamiento, por lo que estas organizaciones comunitarias funcionan con limitaciones de recursos humanos y económicos, funcionando principalmente con la responsabilidad social de las personas de la comunidad.

Palabras claves: Registros Contables, CAPS, Ley 722, Participación Comunitaria.

\section{Introducción}

Este estudio ofrece un diagnóstico de los registros contables realizados por los Comités de Agua Potable y Saneamiento (CAPS), en las comunidades de El Verdún, Yolaina, Los Ángeles, Nuevo León y La Esperanza, todas del municipio de Nueva Guinea en el periodo 2014, el objetivo es conocer la forma de cómo realizan los registros contables y así poder ofrecer propuestas que les permitan mejorar su contabilidad y con ello desarrollar adecuados procesos de rendición de cuentas; aumentar la credibilidad y confianza ante las personas beneficiadas y disminuir los riesgos por el inadecuado manejo de los recursos de estas organizaciones.

Los CAPS son organizaciones sin fines de lucro y no tienen acompañamiento por parte de autoridades vinculadas con el servicio. Estos juegan un papel muy importante, velando por el bienestar de su colonia, por garantizar un servicio básico tan valioso para la comunidad. Se puede decir que los CAPS en estudio trabajan de diversas maneras, pues cada uno de ellos es autónomo y funciona en base a las experiencias y capacidades de las personas que están al frente de estas organizaciones.

\footnotetext{
1 Lic. En Contabilidad Pública y Auditoria. yuniethaguilar@gmail.com

2 Lic. En Contabilidad Pública y Auditoria. mayrelisjar@hotmail.com

3 Candidata a Doctora en Educación con Especialidad en Mediación Pedagógica, docente URACCAN. mibsamaragon@yahoo.com
} 
El estudio reviste de gran utilidad para conocer los registros contables de los CAPS, debido a que en la mayoría de las colonias donde se cuenta con el servicio de agua potable es administrado por la comunidad a través de los CAPS, quienes deben llevar un registro ordenado de todas las actividades que se derivan de este servicio. En tal sentido, la URACCAN por medio de estudiantes finalistas deja aportes que pueden considerarse como elemento importante en la toma de decisiones que redunde en mejora de su quehacer.

Se recomienda asumir las normativas existentes para el manejo contable de los CAPS. También se sugiere que se gestione mayor apoyo con las entidades gubernamentales; asimismo dar continuidad con capacitaciones en temas contables, desarrollar asambleas comunitarias para la rendición de cuentas, realizar alianzas con las universidades para que los estudiantes de las carreras administrativas puedan apoyar por medio de sus prácticas pre profesionales, y que tengan su propia oficina para que los usuarios lleguen a efectuar su pago y permanezcan todos los soportes contables en un solo lugar, y por último se le recomienda a los comités de agua potable y saneamiento CAPS hacer adopción del manual de contabilidad y control interno definido especialmente para ellos situado en la unidad técnica territorial de la alcaldía municipal.

\section{Revisión de literatura}

\section{¿Qué son los CAPS?}

Son organizaciones sin fines de lucro, de manera voluntaria, y electos democráticamente, tienen a su cargo la administración, operación y mantenimiento del servicio de agua potable y saneamiento en la comunidad, con el apoyo de todos los usuarios, a quienes además, rinden cuentas de sus gestiones y actividades, definidos así en la ley Especial de Comités de Agua Potable y Saneamiento, aprobada en Junio del 2010, con el propósito de que se establezcan las disposiciones legales y se constituya la legalización y funcionamiento de los CAPS existentes en el país y de los que en el futuro se organicen a nivel nacional.

\section{¿Cómo funcionan los CAPS?}

La administración o gerencia de los CAPS, según el Art. 16 Ley 722, establece que dependiendo del desarrollo y complejidad de las operaciones de los CAPS, éstos deben establecer una administración a cargo de la parte ejecutiva de las operaciones, disponiendo del personal requerido para tal efecto. A la cabeza de la misma debe estar un administrador o gerente, subordinado a la junta directiva.

Algunas funciones de los CAPS, según la Ley 722 en el Arto. 17, son: a) Convocar a reuniones a los comunitarios para tratar asuntos relativos al acueducto; b) Velar por el buen funcionamiento del servicio, ejecutando las obras necesarias para su conservación y mejoramiento, con la supervisión del Instituto Nicaragüense de Acueductos y Alcantarillados (INAA); c) Autorizar o suspender los servicios domiciliarios conforme el Reglamento y de conformidad con las disposiciones de la autoridad de aplicación y d) Recaudar y administrar los fondos provenientes de las tarifas correspondientes al sistema, contribuciones, rifas y eventos sociales que se realicen para incrementar los recursos del CAPS.

Los registros contables según el Arto.18 Ley 722, son: libros de registro de usuarios, de actas y un libro donde reflejen los ingresos y egresos de los fondos y el movimiento de materiales e insumos. Estos libros deberán ser autorizados, sellados y rubricados por la Oficina de Registro Central de los CAPS, adscrita a INAA, a quien le corresponderá el control y seguimiento de los mismos de conformidad a las normativas y procedimientos que para tales efectos se elaboren y aprueben..

Las formas de rendición de cuenta, para (A. Taisigüe, comunicación personal, 28 de Septiembre, 2014), son:

- Declaración de impuestos a la DGI mensual y anualmente.

- Entregar al Instituto Nicaragüense de Acueductos y Alcantarillados (INAA), memoria de informe de gestión, acta de asamblea, estados financieros y plan del próximo año.

- Entregar informe a la unidad Técnica Ambiental de la Alcaldía Municipal.

- Rendir cuenta a sus miembros pertenecientes a la junta directiva, pobladores con el servicio de agua en las comunidades presentando estados financieros, presupuesto ejecutado y presupuesto del próximo año. 


\section{Materiales y métodos}

El estudio se desarrolló en el 2014, en 5 colonias aledañas al área urbana de Nueva Guinea específicamente en: La Esperanza, Nuevo León, Yolaina, Los Ángeles y El Verdún. Tiene un enfoque cualitativo, y por su profundidad es descriptivo. Es transversal porque se estudió en un tiempo corto.

La unidad de análisis estuvo compuesta por los informantes claves definidos a conveniencia y que reunieran las siguientes características: 2 participantes que formen parte de la junta directiva de cada comunidad, 10 en total y 5 personas por comunidad, que reciben el servicio de agua potable, 25 en total. La fuente secundaria se obtuvo a través de la revisión bibliográfica e internet. Por tratarse de un estudio cualitativo los instrumentos y técnicas se utilizaron fueron entrevistas y algunas encuestas para soportar la información extraída de las entrevistas.

El análisis de los datos se hizo siguiendo los objetivos propuestos en la investigación, lo que permitió dar salida a cada uno de ellos.

\section{Resultados y discusión}

\section{Tipos de registros contables que llevan los CAPS}

Según los informantes expresaban que estos son los tipos de registros contables con los que trabajan, esto indica que los miembros de las juntas directivas de estos CAPS han recibido asesorías y capacitaciones contables, por el tipo de registros que aplican, ya que para realizar cualquiera de estos registros se necesita tener conocimientos en la temática. "Nosotros llevamos registros contables sencillos tales como: libro de acta de usuario, libro de ingresos y egresos, libro diario, libro mayor y caja chica" (Ojeda, Pettiens, Ríos, Mendoza, Toruño, 27/09/14).

Lo anterior denota el uso de registros contables básicos, unos más actualizados que otros; sin embargo, en la revisión documental realizada se pudo observar que en el CAPS de Nuevo León, no cumplen las normativas, ya que el presidente asume más de un cargo en la junta directiva, teniendo un dominio prácticamente total en la toma de decisiones. En el caso del CAPS de La Esperanza de igual manera llevan registros contables, pero la directiva está incompleta. En Los Ángeles tienen un personal suficiente de acuerdo a lo establecido en la ley, tratan de llevar un registro contable básico, utilizando los libros como soportes para dar buena fe y confianza a las personas y en la comunidad de El Verdún, los miembros del CAPS se interesan por el trabajo comunitario manteniendo actualizado los libros de registros señalados anteriormente.

Para nosotros llevar un registro contable significa buen funcionamiento, estabilidad, y sobre todo credibilidad ante la población, eso nos hace sentir mejores personas líderes en quien pueden confiar los habitantes beneficiarios del servicio, nos sentimos satisfechos de poder trabajar en el proyecto de los CAPS Y así contribuir con el bienestar económico y social en nuestra colonia (Ojeda, Ríos, Mendoza, Toruño 27-28/og/14).

Las argumentaciones anteriormente descritas explican la importancia que tienen los registros contables. Estas directivas tienen una visión amplia del trabajo comunitario, a pesar de la poca participación de la población que mencionan ellos mismos.

\section{Proceso de rendición de cuentas de los CAPS}

La forma como los CAPS rinden cuentas mediante asambleas comunitarias donde cada miembro de las juntas directivas estudiadas se encargan de divulgar por medio de convocatorias escritas, invitaciones verbales y avisos radiales a las personas usuarias del servicio, todo esto con la finalidad de reflejar cada uno de los movimientos monetarios que ha generado el CAPS en un periodo establecido. De manera que los miembros de las juntas buscan la forma más fácil y entendible para transmitir la información, como: papelógrafos, pizarra, fotocopias.

En la revisión documental, se pudo verificar que existen convocatorias escritas y algunos recibos y notas de invitaciones radiales, es decir se hacen procesos de rendición de cuentas, tal y como señalan los miembros de la junta directiva que fueron entrevistados y las encuestas de los usuarios. 
A partir de las fundamentaciones de los miembros de la directiva y los habitantes de las colonias, en cada una de las reuniones que se realizan para rendir cuentas, las personas que dirigen los CAPS tratan de ser lo más claro posible, abordan lo realizado en un determinado tiempo, lo anterior sugiere la existencia de habilidades y dinamismo a la hora de transmitir la información a los demás; empero, los comunitarios son poco participativos e interesados a la hora de hacer presencia en las reuniones y exigir información del funcionamiento de los CAPS.

Una estrategia de transparencia en la rendición de cuentas fue conocida en el CAPS de la colonia El Verdún y La Esperanza quienes consideran que toman en cuenta el 50 más 1 de votos para dar por concluido que las rendiciones de cuenta están aprobadas por parte de las personas beneficiadas del servicio.

Además de lo anterior, en el caso de Los Ángeles, el tesorero de la junta directiva señala que la población poco se involucra en estos procesos, "porque aducen que para eso pagan por el servicio". (José Darío Martínez Pineda, 04/02/2015).

Las rendiciones de cuentas la realizan en diferentes tiempos a excepción de colonia Nuevo León, que hace aproximadamente un año que no han desarrollado este proceso porque la junta directiva no está bien organizada y sólo una minoría se presenta a las reuniones. En colonia Yolaina lo hacen de forma mensual ante toda la junta directiva y a los pobladores de una a dos veces al año. En Los Ángeles, El Verdún y La Esperanza, se realiza cada tres y seis meses, con la presencia de toda su junta directiva.

Todo usuario del servicio de agua potable está en el derecho de pedir cuenta a la junta directiva ya que cuando asiste no va porque quiere ir sino porque es obligación de cada comunitario conocer la estabilidad económica y social del CAPS que lo representa pero si los ciudadanos no asisten no tienen ningún derecho de reclamar de actividades y movimientos que desconoce (Ríos 28/og/14).

Los presidentes de las directivas de las comunidades estudiadas expresaron: "Se hacen reuniones extraordinarias cuando creemos que es de suma importancia convocar a toda la población para informarles de algo y las ordinarias las realizamos cada tres o seis meses como un acuerdo comunitario".

Las anteriores afirmaciones describen que las personas que están al frente de estos comités, tienen en cuenta la participación de los comunitarios para las asambleas de rendiciones de cuenta, eso también denota el compromiso social comunitario que han asumido estos líderes y lideresas. Por otro lado se percibe que no toda la población tiene compromiso de participar en las actividades organizadas y convocadas por la Junta Directiva de los CAPS, lo que podría desmotivar las acciones y esfuerzos de sus líderes, pero a la vez, facilitar la práctica no transparente del manejo de los recursos.

Las argumentaciones de los habitantes fueron similares en las colonias estudiadas y afirmaron que los miembros directivos los citan a reuniones cada tres meses, seis y anualmente para hacerles saber cómo están con los fondos recaudados por el servicio que estos pagan, ofreciendo información sobre los movimientos que se han hecho durante un período establecido, de una manera clara, entendible y requiriendo de la aprobación de la población como lo establece la ley reguladora de los CAPS.

\section{Aplicación de las normativas en la contabi- lidad utilizada en los CAPS}

La apropiación de la ley ha sido uno de los retos más difíciles que enfrentan los CAPS según los mismos entrevistados, ya que existen debilidades en cuanto al manejo y aplicación correcta de la misma, en unos CAPS más que en otros, como ya se ha manifestado; no obstante, ellos hacen alusión al interés e importancia de llevar los registros como indican las normativas.

Cabe señalar que los Comité de Agua Potable y Saneamiento (CAPS) están exentos de todos los impuestos sean fiscales o municipales, es decir no tienen que pagar impuestos por las compras que realicen en función del cumplimiento de sus objetivos propios, estos son únicamente retenedores.

Las personas encuestadas afirman, que la junta directiva les convocan a reuniones para darles a conocer los ingresos y egresos de los CAPS, así como los avances o reformas que han venido surgiendo con respecto al manejo de los estos, como el 
contar con su propio laboratorio donde se le podrá dar un mejor tratamiento al agua para mejorar la calidad de este.

Los CAPS de las colonias La Esperanza, y El Verdún están en un proceso de mejorar la aplicación de las normativas, según la información ofrecida se proponen contar con la ayuda por parte de la población, de manera breve agregaban que muchas veces se sienten desanimados por la poca participación que brinda el poblado beneficiario del servicio, las secretarias hacen los cobros a los usuarios y la directiva en conjunto asumen el rol de operación y mantenimiento del sistema de agua potable (fontanería) sin recibir un salario por estas actividades que realizan.

En la colonia Yolaina por el grado de simplicidad de su CAPS (Mini Acueducto por Gravedad MAG) el tesorero es el encargado de llevar las actividades contables cumpliendo con lo que establece la ley, ya que ninguna persona de los que conforman la directiva lleva doble función.

\section{Alternativas que fortalezcan los registros contables de los CAPS}

Contar con un sistema de registro estructurado y organizado, como lo establecen las normativas sugeridas en la ley 722, que les proporcione mayor credibilidad ante la población. Capacitación en temas contables y declaración de los impuestos exigidos por la DGI (Dirección General de Ingresos), para un mejor manejo de los instrumentos o documentos que deben poner en práctica.

Definir un sólo lugar que les permita resguardar toda la información y documentos concernientes al trabajo que realizan los CAPS. Capacitarse o capacitar a un miembro del Comité para la realización de los informes. Mencionan la necesidad de mayor acompañamiento de las entidades públicas, para garantizar mejores procesos de organización comunitaria y transparencia de las acciones que realizan las organizaciones comunitarias.

Motivar a la población a una mayor participación e involucramiento en las actividades de la comunidad y específicamente al trabajo de los CAPS. Finalmente se mencionó la necesidad de que los jóvenes participen más activamente en las actividades de su comunidad.
Aquí una de las opiniones de los informantes: "Bueno ser bien cuidadoso con el fondo, porque no es del CAPS, sino de la población y para mejora del sistema" (José Darío Martínez Pineda, 04/02/2015) "Mire tenemos problemas con el asunto de los informes y queremos una capacitación y pagamos mensual a una persona para que nos ayude con lo de la DGI. Necesitamos una oficinita privada para reunirnos y guardar los documentos" (Justo Pastor Reyes Sánchez, 04/02/2015)

\section{Conclusiones}

Los tipos de registros contables que utilizan los CAPS en las colonias estudiadas son: libro diario, de acta, registro de usuarios, caja chica, libro de ingresos y egresos, que obedece a una contabilidad básica y ajustada a lo que establece la ley 722; sin embargo, unos lo realizan de manera más ordenada y clara que otros.

La mayoría de los CAPS, rinden cuentas a la población de las actividades que realizan, presentan un informe financiero de los ingresos y egresos generados, con diferente periodicidad, que va desde trimestral, semestral y anual, cumpliendo con lo establecido en la normativa o ley 722, que especifica hacerlo una vez al año, y de forma extraordinaria las veces que sean necesarias, a pesar que la población participa escasamente. A excepción del CAPS de Nuevo León, que tiene más de un año de no hacerlo.

En general existe voluntad y aplicación de lo normado en la ley 722 para el manejo contable de los recursos de los CAPS, con diferencias específicas como la funcionabilidad de las juntas directivas que en algunos casos son menos beligerantes que otras. Como ejemplos se menciona el caso de Nuevo León que una misma persona desempeña 3 funciones y devenga dos salarios, en cambio en el caso de El Verdún, la junta directiva se interesa porque la población esté satisfecha de lo que hacen y exigen aprobación de los informes presentados a los pobladores con la asistencia del $50 \%$ más 1.

Por otro lado y un aspecto igualmente relevante que se encontró en la investigación es la falta de acompañamiento de algunas instituciones públicas y gobierno local que tienen la responsabilidad de apoyarles y regular tales acciones como: Alcaldía Municipal, INAA como ente regular, con la ayuda de MARENA, MAGFOR, INAFOR, ENACAL y MINSA, por tener competencias en garantizar los servicios básicos de calidad a la población. 
